\title{
Determinants of delayed diagnosis and treatment of tuberculosis in Cambodia: a mixed-methods study
}

\author{
Alvin Kuo Jing Teo ${ }^{1 *}$ (D) Chetra Ork², Sothearith Eng ${ }^{2}$, Ngovlyly Sok ${ }^{2}$, Sovannary Tuot ${ }^{2}$, Li Yang Hsu ${ }^{1,3}$ and \\ Siyan $\mathrm{Yi}^{1,2,4,5}$
}

\begin{abstract}
Background: Cambodia is among the 30 countries in the world with the highest burden of tuberculosis (TB), and it is estimated that $40 \%$ of people with TB remain undiagnosed. In this study, we aimed to investigate the determinants of delayed diagnosis and treatment of TB in Cambodia.

Methods: This mixed-method explanatory sequential study was conducted between February and September 2019 in 12 operational districts in Cambodia. It comprised of a retrospective cohort study of 721 people with TB, followed by a series of in-depth interviews. We assessed factors associated with time to TB diagnosis and treatment initiation using Cox proportional hazards model. Subsequently, we conducted in-depth interviews with 31 people with TB purposively selected based on the time taken to reach TB diagnosis, sex, and residence. Transcripts were coded, and thematic analyses were performed.

Results: The median time from the onset of symptoms to TB diagnosis was 49 days (Interquartile range [IQR]: 21-112). We found that longer time to diagnosis was significantly associated with living in rural area (Adjusted hazards ratio $[a H R]=1.25$; 95\% confidence interval [C]: 1.06-1.48); TB symptoms-cough (aHR: 1.52; 95\% Cl: 1.18-1.94), hemoptysis (aHR 1.32; 95\% Cl: 1.07-1.63), and night sweats (aHR: 1.24; 95\% Cl: 1.05-1.46); seeking private health care/self-medication (aHR: 1.23; 95\% Cl: 1.04-1.45); and higher self-stigma (aHR: 1.02; 95\% Cl: 1.01-1.03). Participants who received education level above the primary level were inversely associated with longer time to diagnosis (aHR: 0.78 ; $95 \%$ Cl: 0.62-0.97). The median time from TB diagnosis to the initiation of treatment was two days (IQR: 1-3). The use of smear microscopy for TB diagnosis (aHR: 1.50; 95\% Cl: 1.16-1.95) was associated with longer time to treatment initiation. Seeking private health care and self-medication before TB diagnosis, lack of perceived risk, threat, susceptibility, and stigma derived qualitatively further explained the quantitative findings.
\end{abstract}

Conclusions: TB diagnostic delay was substantial. Increasing public awareness about TB and consciousness regarding stigma, engaging the private healthcare providers, and tailoring approaches targeting the rural areas could further improve early detection of TB and narrowing the gap of missing cases in Cambodia.

Keywords: Tuberculosis, Delayed diagnosis, Health-seeking behavior, Cambodia

\footnotetext{
* Correspondence: alvin.teo@aol.com

'Saw Swee Hock School of Public Health, National University of Singapore,

National University Health System, Singapore, Singapore

Full list of author information is available at the end of the article
} 


\section{Background}

Tuberculosis (TB) is a leading infectious cause of morbidity and mortality worldwide, accounting for 10 million new cases and 1.2 million deaths in 2018 [1]. Cambodia is one of the 30 countries with the world's highest burden of TB, with an estimated incidence of active TB of 302 (95\% CI: 169-473) per 100000 population in 2018 [1]. Led by the National Center for Tuberculosis and Leprosy Control (CENAT), the national TB control program was set up to control and treat $\mathrm{TB}$, including the introduction and country-wide expansion of directly observed therapy short-course (DOTS) since 1994 [2]. As in many other high TBburden countries, passive case finding (PCF) is the default setup for TB case finding at health centers where people with TB symptoms seek care, and the providers can identify the conditions [3]. This strategy is, however, inadequate to detect and measure the burden of undiagnosed TB in the community. Active case finding (ACF), a strategy that has gained traction in recent years, was found to increase case detection in Cambodia [4]. Yet, despite increased efforts to find the missing cases, every fourth person with TB goes undetected in Cambodia [1], similar to the proportion reported globally in 2018 [1].

Prolonged delays have been associated with further transmission of the infection in the community [5] and thus posed a great challenge to TB elimination efforts globally $[6,7]$. Therefore, understanding the specific determinants of delayed diagnosis can be used as a practical guide to enhance outreach programs, increase community engagement to reach missing cases, and to improve TB control strategies. Recent systematic reviews have reported empirical evidence associating socio-demographic, clinical, health system, and economic factors with delayed diagnosis and treatment of TB [8-10]. In Cambodia, Sundaram and colleagues have reported that strong preference for private healthcare services, lack of awareness of TB symptoms, and misbeliefs regarding TB (such as TB is a hereditary disease and the ability to recover without treatment) may delay seeking TB diagnosis [11]. However, the sociocultural and clinical determinants of delayed diagnosis have yet to be thoroughly examined. Furthermore, other individual-level factors such as stigma have been associated with health inequalities and a barrier to health care [12], but its impact on health-seeking decisions and TB diagnosis were inconclusive [13, 14]. In this study, we aimed to explore the determinants of delayed diagnosis and treatment of TB in Cambodia.

\section{Methods}

We applied a mixed-method explanatory sequential study design comprising a retrospective cohort study, followed by in-depth interviews (IDIs) with people with TB in Cambodia. The National Ethics Committee for Health
Research Cambodia (NECHR) (NECHR reference: 024/ NECHR) and National University of Singapore (NUS) Institutional Review Board (IRB) (NUS IRB reference: H-19015) approved the study. Informed consent was obtained from all respondents before study enrolment.

\section{Retrospective cohort study \\ Setting}

We conducted a retrospective cohort study on people with $\mathrm{TB}$ in 12 operational districts (OD) in 10 provinces in Cambodia. We selected 100 health centers with a probability proportional to size (by the total population each health center served) sampling without replacement from the total number of health centers $(n=143)$ in the 12 ODs.

\section{Study population}

In the selected ODs, trained data collectors recruited participants aged 18 and above who were diagnosed with TB within 1 month of survey implementation, regardless of the history of previous TB treatment, HIV status, and the drug resistance status. Bacteriological status of participants was determined by either smear microscopy or GeneXpert MTB/RIF. For participants who were tested negative, further assessment and TB diagnosis were made by clinicians based on clinical and laboratory grounds, and chest radiographic abnormalities [15]. TB workup and diagnoses were done in accordance with the national guideline [15]. We excluded those who refused to participate.

\section{Key variables and definition}

We collected information on socio-demographic characteristics, presence of other known medical conditions (one or more co-morbidities would constitute a yes versus no), TB symptoms before diagnosis (and the date of onset), knowledge and beliefs on TB, TB-related stigma experiences, and psychological distresses using a paperbased questionnaire. We asked if study participants had sought healthcare prior to TB diagnosis and the facilities that they had visited. In this study, private health care facilities included private pharmacies, private general practitioners, private hospitals, and traditional healers. Selfmedication referred to the use of medications without professional advice. Public health facilities referred to government hospitals and health centers. We dichotomized the level of residence urbanization into "urban" and "rural" based on the Ministry of Planning's framework $[16,17]$. Using the WHO TB knowledge, attitude, and practices survey [18] and the General Health Questionnaire (GHQ)-12 [19, 20], we measured participants' TB knowledge and the psychological distress they experienced before TB diagnosis, respectively (Supplementary Materials). Study participants who scored above the median [21] were regarded as having good TB knowledge. 
We measured TB stigma using validated scales developed by Van Rie and colleagues [22, 23]. Self-stigma (12 items) and perceived stigma by the community (11 items) were measured on a Likert scale of 0 to 3 $(0=$ "strongly disagree" and $3=$ "strongly agree"). The scales measured thoughts and feelings of people with TB (self-stigma) and the perceptions of people with TB regarding how the community feels about people with TB (perceived stigma by the community) [22]. Based on the four-point Likert scale, the minimum score was 0 , and the maximum possible score was 36 and 33, respectively. Summary stigma scores were standardized to 50 with higher scores indicating a higher level of stigma.

The main outcomes of interest in this study were diagnostic and treatment delay. We defined diagnostic delay as the duration (time in days) between the onset of symptoms first recognized and self-reported by study participants and the final diagnosis of TB. Treatment delay was defined as the duration (time in days) between TB diagnosis and treatment initiation.

\section{Data collection procedures and quality assurance}

Trained data collectors conducted face-to-face interviews at the health centers with study participants using a paper-based questionnaire. We pre-tested the questionnaire with eight people with $\mathrm{TB}$ and $\mathrm{TB}$ survivors (data excluded from the main study). Data collectors were trained to use prompts such as significant cultural and public holidays in Cambodia to aid participants in recalling the most accurate date of onset of TB symptoms possible. Participants were reimbursed with United States dollar (USD) 5 at the end of the interview. We obtained information on the final diagnosis of $\mathrm{TB}$ and treatment initiation date from the facilities where TB diagnosis was made. To ensure the quality of the data, the study team conducted several supervisory field trips, and teleconference meetings with the field team were held fortnightly. Before data entry, the questionnaires were checked for completeness. Four members of the research team entered data in the questionnaires into KoBoToolbox (Harvard Humanitarian Initiative, Cambridge, Massachusetts, USA) [24]. Regular checks on the entered data were conducted. Inconsistencies were discussed, and discrepancies were resolved by revisiting the original questionnaires. Data were exported into Microsoft Excel (Microsoft Office Professional Plus 2016, Microsoft Corp., Redmond, Washington, USA) for data cleaning before analyses.

\section{Statistical analyses}

First, we described and presented the data using frequencies and percentages for categorical variables and median with interquartile range (IQR) or mean with standard deviation $(S D)$ for continuous variables. We assessed the determinants of diagnostic and treatment delay using time-to-event analyses. The time to events - TB diagnosis and initiation of TB treatment-were measured in days. In this study, events were regarded to have occurred when a TB diagnosis was made, or TB treatment was initiated. As all the participants in this study were diagnosed with TB and initiated on treatment, no data were censored. However, participants $(n=100)$ who started on treatment on the same day (time to event $=0$ ) as they were diagnosed were not included in the risk set. Log-rank test and univariate Cox proportional hazard regression were used to estimate the statistical significance of categorical and continuous variables, respectively. Epidemiologically relevant variables and other exposure variables with $P$-value $\leq 0.1$ in univariate analyses were included in the Cox proportional hazard model. We checked model fit using Akaike Information Criteria [25] and assessed the assumption of proportional hazards using Schoenfeld global test of residuals [26], and no violations were observed (diagnostic delay model: $P=0.428$, treatment delay model: $P=0.840$ ). We evaluated the fit of the final models using Cox-Snell residuals. Hazard ratios $(H R)$ were reported with $95 \%$ confidence interval $(C I)$, and a 2 -tailed $P$-value $<0.05$ was considered significant. All data were analyzed using STATA 14 (StataCorp LP, Texas, United States of America).

\section{In-depth interviews}

Study population

Study participants for the qualitative IDIs were purposively selected using maximum variation sampling from the cohort recruited in the survey described above. To ensure equal representation of perspectives from persons who experienced diagnostic delay and those who were diagnosed early in the course of their disease, we selected participants from the both extremes of the time to diagnosis spectrum $-<15$ days (short delay) and $>$ 100 days (long delay) - and stratified them according to sex (men/women) and residence (urban/rural). We approached 37 individuals, and six people refused to participate due to illness and work priorities. In total, 31 people with TB were interviewed.

\section{Data collection}

We developed a semi-structured interview guide that comprised of elements related to participants' illness experiences, diagnosis, and treatment-seeking behavior. Questions and probes were focused on 1) knowledge and perception of $\mathrm{TB}$ as a disease; 2) experiences with seeking diagnosis and treatment for $\mathrm{TB}$, with clinical and/or traditional approaches; and 3) barriers and facilitators experienced in seeking diagnosis and treatment. The semi-structured interview guide was pilot tested and revised accordingly. The IDIs were conducted in four ODs in September 2019 by CO, SE, and NS, who 
were trained in qualitative research. We matched the interviewers and interviewees by sex to minimize potential biases in participants' responses. Most of the interviews were conducted $1: 1$ in a private room at the health centers nearest to participants' homes. We also conducted some interviews at participants' homes, and on some occasions, family members were present. All the interviews were conducted in Khmer, and each interview lasted between 30 to $60 \mathrm{~min}$. Interviews were audiorecorded, and field notes were taken during the interviews. Participants' received USD 10 in return for their time and effort.

\section{Data analyses}

$\mathrm{CO}, \mathrm{SE}$, and NS transcribed all the IDIs verbatim. Transcripts in Khmer were then translated to English for analyses. The translated English transcripts were reviewed against the original version for verification by SE. Annotation and analysis of complete transcripts were conducted using NVivo (Version 10, QSR International, Burlington, Massachusetts, USA). Textual references to the topics of interest were retrieved and categorized using thematic analysis. AKJT and SE independently read and coded the transcripts characterized by 1) those with shorter delay to diagnosis and 2) those with a longer delay to diagnosis. We derived initial themes based on the semi-structured interview guide in developing a codebook of structural codes. We added emergent codes accordingly to the codebook. No new concepts relevant to the objective of this study were identified after interviewing 31 individuals, and data saturation were reached. Conclusions were drawn through the interpretation of the derived themes and the triangulation of qualitative data with quantitative findings.

\section{Results}

\section{Retrospective cohort study}

In total, 721 people with $\mathrm{TB}$ participated in this study (Table 1). The median age was 61 years (IQR: $52-71$ ), and $36.9 \%$ were living in an urban setting. The cohort comprised of men (53.1\%), individuals who were married (77.8\%), and individuals who had at least primary education (84.5\%). Forty percent of the participants were diagnosed with bacteriologically confirmed TB, and GeneXpert MTB/RIF test informed most of the TB diagnosis. The median distance from the place of residence to the nearest public health facility was four kilometers (IQR: 2-6). Sixty-six percent of the study participants sought private health care and/or self-medicated before TB diagnosis. The median knowledge score reported by study participants was 9. The mean scores for self-stigma and perceived stigma by the community were $25.1(S D=6.9)$ and $26.0(S D=7.2)$, respectively, and they were normally distributed. The Cronbach's alphas for the self-stigma was
0.878 and for the perceived stigma by the community scale was 0.877 .

The median time from onset of symptoms to TB diagnosis was 49 days (IQR: 21-112). In univariate analysis, a longer time to TB diagnosis was significantly associated with TB symptoms (cough, hemoptysis, fever, weight loss, and night sweats), education level, seeking private health care/self-medication, poor TB knowledge, experiencing psychological distress after falling sick (higher GHQ-12 scores), higher self-stigma, and TB diagnosis informed by smear microscopy (Table 2). In the multivariate model adjusted for age, gender, and residence, a longer time to TB diagnosis remained significantly associated with rural residence (Adjusted hazards ratio $[\mathrm{a} H R]=1.25 ; 95 \% C I$ : $1.06-1.48, P=0.01)$; TB symptoms-cough $(\mathrm{a} H R=1.52 ; 95 \% C I: 1.18-1.94, P=0.001)$, hemoptysis $(\mathrm{a} H R=1.32 ; 95 \% C I: 1.07-1.63, P=0.01)$, and night sweats $(\mathrm{a} H R=1.24 ; 95 \% C I: 1.05-1.46, P=$ $0.01)$; seeking private health care/self-medication $(\mathrm{a} H R=$ 1.23; 95\% CI: 1.04-1.45, $P=0.01$ ); and higher self-stigma $(\mathrm{a} H R=1.02 ; 95 \% C I: 1.01-1.03, P=0.003)$. Participants who received education level above the primary level were inversely associated with longer time to diagnosis $(\mathrm{a} H R=0.78 ; 95 \%$ CI: 0.62-0.97, $P=0.03)$.

The median time from TB diagnosis to the initiation of treatment was two days (IQR 1-3). In univariate analysis (Table 2), a longer time to TB treatment initiation was significantly associated with TB symptoms (cough, and weight loss) and TB diagnosis informed by smear microscopy. In the multivariate model adjusted for age, gender, and residence, a longer time to treatment initiation remained significantly associated only with the use of smear microscopy for $\mathrm{TB}$ diagnosis $(\mathrm{a} H R=1.50$; 95\% CI: 1.16-1.95, $P=0.002)$.

\section{In-depth interviews}

Among the 31 IDIs, half were classified as having short delays and were living in an urban setting. The median age was 56years (IQR: 45-68). We interviewed 18 men and 13 women (Table 3). An overview of the results is presented in Table 4.

\section{Barriers to TB care-seeking}

Participants were not aware and felt that they were not at risk for $\mathrm{TB}$ and therefore delaying care-seeking. The lack of awareness and the perceived risk was compounded by the absence of symptoms or features perceived to be present among people with TB, such as severe cough and appearing underweight. For some participants, the long-distance or inability to travel for services was a barrier to care-seeking.

"I doubted I would have TB. I only had a cough for several days and was exhausted." (IDI17, 64yo, male, urban, long delay) 
Table 1 Participants characteristics and time from onset of symptoms to TB diagnosis

\begin{tabular}{|c|c|c|c|c|c|}
\hline Variables & Median & IQR & Variables & Median & IQR \\
\hline Distance from home to health facility, in kilometer & 4 & $2-6$ & No & 330 & 45.8 \\
\hline \multirow[t]{2}{*}{ Age, in years } & 61 & $52-71$ & Chills & & \\
\hline & Frequency & $\%$ & Yes & 126 & 17.5 \\
\hline Total participants & 721 & 100.0 & No & 595 & 82.5 \\
\hline \multicolumn{3}{|l|}{ Residence } & \multicolumn{3}{|l|}{ Weight loss } \\
\hline Urban & 266 & 36.9 & Yes & 482 & 66.9 \\
\hline Rural & 455 & 63.1 & No & 239 & 33.1 \\
\hline \multicolumn{3}{|l|}{ Sex } & \multicolumn{3}{|l|}{ Night sweats } \\
\hline Male & 383 & 53.1 & Yes & 352 & 48.8 \\
\hline Female & 338 & 46.9 & No & 369 & 51.2 \\
\hline \multicolumn{3}{|l|}{ Education level ${ }^{\mathrm{a}}$} & \multicolumn{3}{|l|}{ Health care seeking prior to TB diagnosis ${ }^{c}$} \\
\hline Primary and lower & 605 & 84.5 & Public health facilities & 244 & 33.8 \\
\hline Above primary & 111 & 15.5 & Private health facilities/self-medication & 477 & 66.2 \\
\hline \multicolumn{3}{|l|}{ Marital status } & \multicolumn{3}{|l|}{ TB knowledge $^{d}$} \\
\hline Never married & 31 & 4.3 & Poor & 179 & 24.8 \\
\hline Currently married & 561 & 77.8 & Good & 542 & 75.2 \\
\hline Widowed/divorced & 129 & 17.9 & \multicolumn{3}{|c|}{ Perception about the seriousness of TB as a disease ${ }^{a}$} \\
\hline \multicolumn{3}{|l|}{ Ever smoked } & Very serious & 275 & 38.3 \\
\hline Ever (current and past smokers) & 216 & 30.0 & Not very serious & 444 & 61.7 \\
\hline Never & 505 & 70.0 & Self-perceived risk of getting $\mathrm{TB}^{\mathrm{a}}$ & & \\
\hline \multicolumn{3}{|l|}{ Current smoker } & Yes, at-risk & 382 & 56.8 \\
\hline Current smoker & 132 & 18.4 & No, not at-risk & 291 & 43.2 \\
\hline Not current smoker & 587 & 81.6 & Total General Health Questionnaire-12 sco & & \\
\hline \multicolumn{3}{|l|}{ Current alcohol use $e^{a, b}$} & $\leq 3$ & 364 & 50.5 \\
\hline Non-drinkers & 509 & 71.1 & $>3$ & 357 & 49.5 \\
\hline Drinkers & 207 & 28.9 & \multirow{11}{*}{\multicolumn{3}{|c|}{$\begin{array}{l}S D \text { Standard deviation, IQR Interquartile range, TB Tuberculosis } \\
\text { a Exclude missing values } \\
\text { b Drinkers reported frequency of alcohol use that ranges from once a month } \\
\text { or less to } 4 \text { times or more per week. Non-drinkers refer to teetotalers } \\
\text { " Participants were asked if they have sought health care prior to TB diagnosis } \\
\text { and if so, the facilities that they have visited. Private health facilities referred } \\
\text { to pharmacy, private general practitioner, and traditional healer. Self- } \\
\text { medication referred to the use of medications without professional advice. } \\
\text { Public health facilities referred to government hospitals and health centers } \\
\text { d Evaluated based on the answers from } 8 \text { questions regarding the } \\
\text { characteristics, symptoms of TB, route of transmission, prevention, and } \\
\text { treatment of TB with a total score of } 13 \text { (median }=9 \text { ). Respondents were } \\
\text { regarded as having poor TB knowledge if they scored the median and below } \\
\text { and good TB knowledge if they scored above the median } \\
\text { "Evaluated based on the total score of the } 6 \text { negative items. Scoring method: } \\
0-0-1-1, \text { with } 0=\text { "less than usual", } 0=\text { "no more than usual", } 1=\text { "rather more } \\
\text { than usual", or } 1=\text { "much more than usual" }\end{array}$}} \\
\hline \multicolumn{3}{|l|}{ Presence of other known medical conditions } & & & \\
\hline Yes & 523 & 72.5 & & & \\
\hline No & 198 & 27.5 & & & \\
\hline Type of TB & & & & & \\
\hline Bacteriologically confirmed TB & 284 & 39.4 & & & \\
\hline Clinician diagnosed TB & 437 & 60.6 & & & \\
\hline \multicolumn{3}{|l|}{ Type of diagnostic tests performed } & & & \\
\hline GeneXpert & 605 & 83.9 & & & \\
\hline Smear microscopy & 116 & 16.1 & & & \\
\hline \multicolumn{3}{|c|}{ than usual", or $1=$ "much more than usual" } & & & \\
\hline Yes & 638 & 88.5 & \multirow{7}{*}{\multicolumn{3}{|c|}{$\begin{array}{l}\text { Participants with short delay reported the lack of per- } \\
\text { ceived threat of TB to their health and competing prior- } \\
\text { ities such as work and family commitments as barriers to } \\
\text { TB care-seeking. Several participants with longer delay to } \\
\text { diagnosis indicated care seeking at private health facilities } \\
\text { or self-medication when symptoms surfaced, many of } \\
\text { which occurred frequently and repetitively prior to TB } \\
\text { diagnosis. }\end{array}$}} \\
\hline No & 83 & 11.5 & & & \\
\hline Hemoptysis & & & & & \\
\hline Yes & 124 & 17.2 & & & \\
\hline No & 597 & 82.8 & & & \\
\hline Fever & & & & & \\
\hline Yes & 391 & 54.2 & & & \\
\hline
\end{tabular}

Table 1 Participants characteristics and time from onset of symptoms to TB diagnosis (Continued)

symptoms to TB diagnosis (Continued)

$S D$ Standard deviation, IQR Interquartile range, TB Tuberculosis

Exclude missing values facilities referred

to pharmacy, private general practitioner, and traditional healer. Self作 and good TB knowledge if they scored above the median

e Evaluated based on the total score of the 6 negative items. Scoring method: $0-0-1-1$, with $0=$ "less than usual", $0=$ "no more than usual", $1=$ "rather more

Participants with short delay reported the lack of perceived threat of TB to their health and competing priorities such as work and family commitments as barriers to TB care-seeking. Several participants with longer delay to diagnosis indicated care seeking at private health facilities which occurred frequently and repetitively prior to $\mathrm{TB}$ 


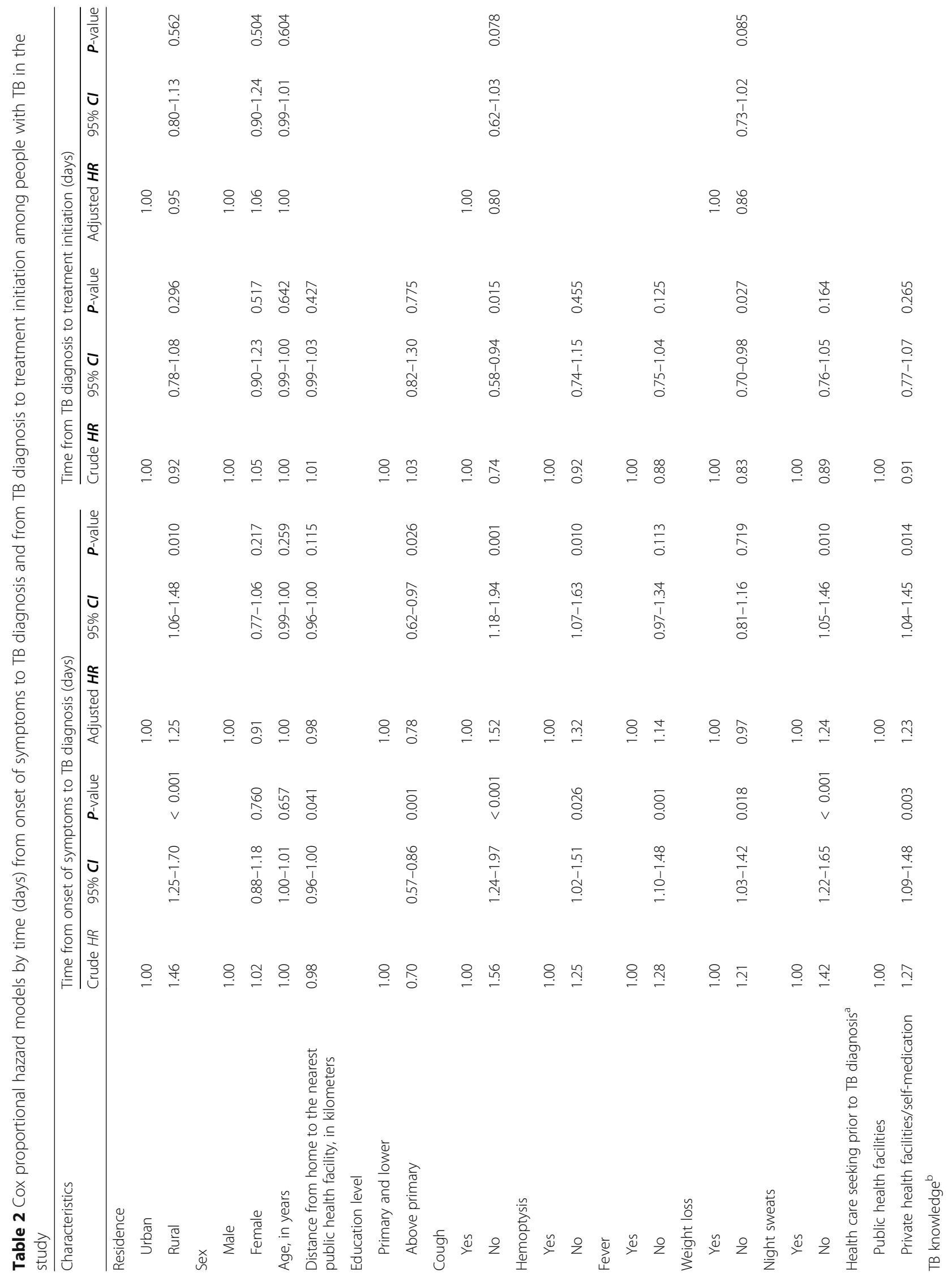




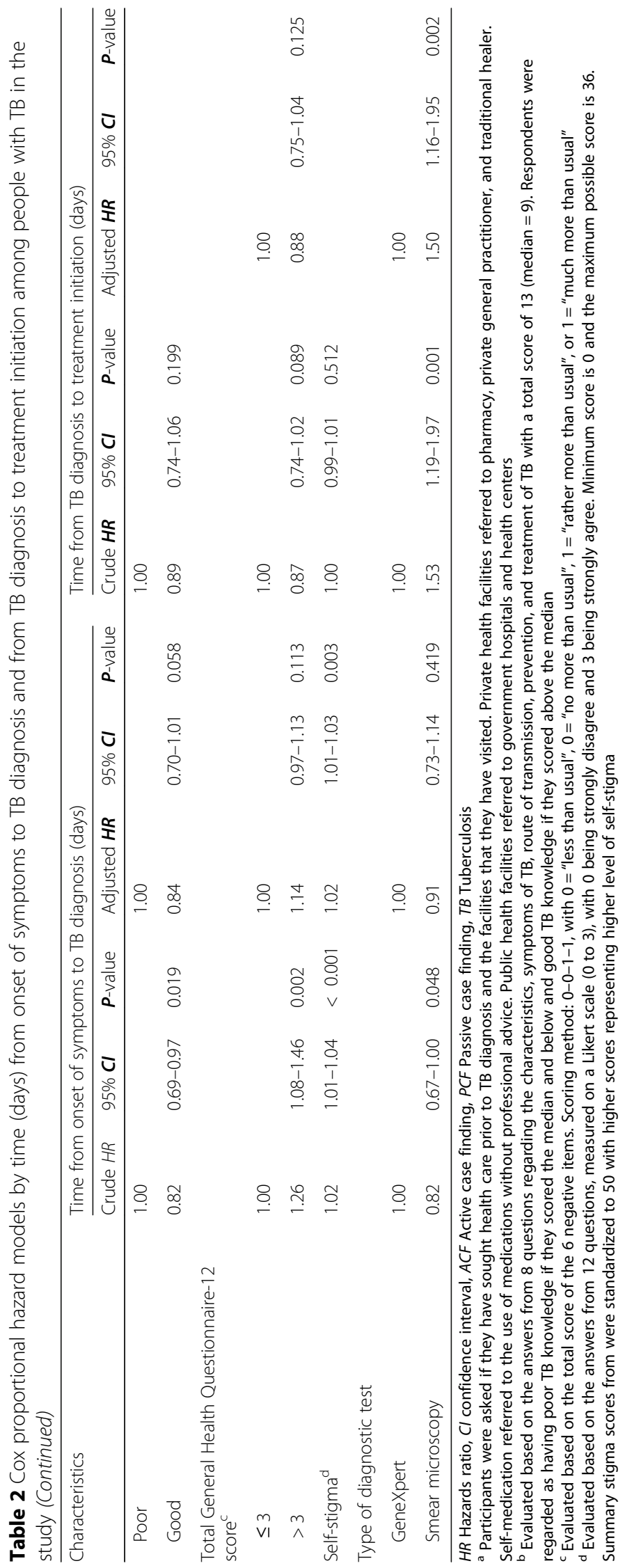


Table 3 Characteristics of in-depth interviews participants

\begin{tabular}{lll}
\hline & Frequency & $\%$ \\
\hline Age, in years (median, IQR) & $56(45-68)$ & \\
Sex & & 58.1 \\
$\quad$ Male & 18 & 41.9 \\
$\quad$ Female & 13 & \\
Residence & & 51.6 \\
$\quad$ Urban & 16 & 48.4 \\
Rural & 15 & \\
Time to TB diagnosis & & 51.6 \\
$\quad$ Short delay & \\
Long delay & & 48.4 \\
\hline
\end{tabular}

IQR Interquartile range, $T B$ Tuberculosis

${ }^{a}$ Time from onset of TB symptoms to TB diagnosis: $<15$ days

${ }^{\mathrm{b}}$ Time from onset of TB symptoms to TB diagnosis: > 100 days

"I didn't go, I just didn't care. Until it got really serious, then I go [to seek care]" (IDI11, 76yo, female, rural, short delay)

"I wanted to go as well. If I have a lot of time, I just wanted to go to the hospital to get treatment to be cured of that disease, and no longer sick. But I really didn't have time, to be honest." (IDI3, 37yo, male, urban, short delay)

"I never went to hospital. When I was [had] cough, I was buying [bought] medicines from pharmacy." (IDI26, 68yo, male, rural, long delay)

\section{Facilitators to TB care-seeking}

Participants from both groups expressed that encouragement from family members and other TB survivors was an impetus to care-seeking, especially when participants were symptomatic and ill. Participants also reported that success stories from TB survivors encouraged them to seek care.

"My mother saw me coughing, and she said that I should go for [TB] screening." (IDI12, 33yo, male, urban, long delay)

Participants with shorter delays to diagnosis consistently reported that fear of infecting others and the ill effects of the conditions on wellbeing, work, and livelihoods prompted TB care-seeking. Many were worried that as they grew weaker, they were unable to go to work and the financial impact that would ensue. Furthermore, the economic woes worsened when significant out-of-pocket payment was required for medical consultations and medications in the private sector, therefore impelled care-seeking in public health facilities where TB services are available for free. Participants who experienced longer delay to diagnosis explained that they only sought care when TB symptoms became intolerable.

"We don't have enough money because when I got sick, I spent 2 thousand to 3 thousand dollars [on multiple consultations and treatments]. I couldn't go to work. I stayed at home." (IDI8, 32yo, female, rural, short delay)

Table 4 Comparison of themes emerged from qualitative interviews between people with shorter delays and people with longer delays to TB diagnosis

\begin{tabular}{|c|c|c|c|}
\hline & \multicolumn{3}{|l|}{ Themes } \\
\hline & Similarities & Short delay & Long delay \\
\hline \multirow[t]{2}{*}{$\begin{array}{l}\text { Barriers to TB } \\
\text { care-seeking }\end{array}$} & $\begin{array}{l}\text { Lack of perceived risk and susceptibility } \\
\text { to TB }\end{array}$ & $\begin{array}{l}\text { Lack of perceived threat of TB } \\
\text { to their own health }\end{array}$ & $\begin{array}{l}\text { Sought private health care/self-medicated } \\
\text { prior to TB diagnosis }\end{array}$ \\
\hline & $\begin{array}{l}\text { Unable to travel to health facilities due } \\
\text { to intolerable symptoms or logistical } \\
\text { constraints }\end{array}$ & $\begin{array}{l}\text { Competing priorities - work, } \\
\text { livelihood, and family responsibilities }\end{array}$ & \\
\hline \multirow[t]{2}{*}{$\begin{array}{l}\text { Facilitators to TB } \\
\text { care-seeking }\end{array}$} & $\begin{array}{l}\text { Encouragement from family members, } \\
\text { and other TB survivors }\end{array}$ & Fear of infecting others & Intolerable symptoms \\
\hline & $\begin{array}{l}\text { Easy access to TB diagnosis provided } \\
\text { by non-governmental organizations }\end{array}$ & $\begin{array}{l}\text { Perceived illness would affect health, } \\
\text { wellbeing, work, and livelihood }\end{array}$ & \\
\hline $\begin{array}{l}\text { Reasons for seeking } \\
\text { private healthcare/ } \\
\text { self-medicate }\end{array}$ & $\begin{array}{l}\text { Better access (facilities are closer } \\
\text { to home) }\end{array}$ & Perceived illness to be less serious & $\begin{array}{l}\text { Perceived to provide better care and } \\
\text { service, and the medicines are more } \\
\text { effective }\end{array}$ \\
\hline $\begin{array}{l}\text { Reasons for seeking } \\
\text { public healthcare }\end{array}$ & Financially affordable & $\begin{array}{l}\text { Perceived to provide better and } \\
\text { safer care }\end{array}$ & Experienced good service in the past \\
\hline TB stigma & & $\begin{array}{l}\text { Felt ashamed/embarrassed because } \\
\text { of TB }\end{array}$ & $\begin{array}{l}\text { Perceived stigma and discrimination } \\
\text { against people with TB }\end{array}$ \\
\hline
\end{tabular}

TB Tuberculosis 


\section{TB stigma}

Another theme that emerged from both groups was perceived stigma against TB. Those with shorter delays to diagnosis indicated that they felt ashamed and embarrassed because of $\mathrm{TB}$.

\section{"I was ashamed. I felt embarrassed because I had} TB." (IDI1, 50yo, male, urban, short delay)

Many participants with longer delay to diagnosis reported both self-perceived and experience of discrimination perpetrated by people around them. Several accounts of participants distanced by members of their community after they were diagnosed were reported.

\section{"I always think like that. I thought that this disease is similar to HIV. People in my village discriminate against these diseases." (IDI23, 58yo, male, rural, long delay)}

"As I was sick, that one knows that I was sick, they didn't dare to talk to us. They walked out while we walked in; so, it's the effect, they know we like this [living with TB], they discriminated us." (IDI12, 33yo, male, urban, long delay)

\section{Discussion}

In this study, we found that the median time from the onset of symptoms to TB diagnosis among people with TB in Cambodia was 49 days, and it is comparable to recent studies conducted in other high TB-burden countries in Asia [27, 28]. We found respondents living in rural areas of the country were more likely to experience a delay in diagnosis. This is consistent with findings from other low- and lower-middle-income countries [29-31], and high TB-burden settings [32]. Despite the similar risk profiles for TB between urban and rural areas in Cambodia [33], delayed TB diagnosis in rural Cambodia where large portions of the population are located [34] raised concerns regarding the differences in structural and social determinants between the dwellings in obtaining timely diagnosis and treatment. IDI participants from rural areas highlighted physical access and logistical barriers in TB care-seeking. However, specific challenges faced by the population living in rural areas should be further investigated. In Cambodia, different active case finding strategies targeting a specific setting and/or population have shown promising results in increasing case yields $[4,35]$, but the impact of these strategies on early identification of TB should be thoroughly examined. Our analyses also showed that participants who had education above the primary level and those with good TB knowledge (statistically not significant) had a shorter time to diagnosis, and it is in line with a recent meta-analysis on TB delayed diagnosis conducted among lower-middle-income countries [8]. We found significant correlations between TB knowledge and participants' perception of the seriousness of TB $(P<0.001)$ and their self-perceived risk of contracting TB $(P=0.01)$ (Supplementary Table 1). This relationship was further explained by IDI participants as barriers to TB careseeking. Participants who had lower education levels might have limited access to information about TB and therefore be less aware of the consequences of TB to themselves and their close contacts.

Our results showed that respondents who reported experiencing onset symptoms of hemoptysis and cough were less likely to delay their diagnosis. In conformity with two systematic reviews [8, 32], hemoptysis was perceived as more serious than cough, and people with these symptoms were more likely to seek care immediately. IDI participants who experienced longer delay to diagnosis also identified that care-seeking at public health facilities was only impelled when symptoms became unbearable. We found contrasting results for the onset symptoms of cough. Most studies reported a positive relationship between cough and delayed diagnosis as it overlaps with the manifestations of other respiratory infections and smoking [36-38]. Unfortunately, we did not collect data regarding concurrent respiratory infections during the onset of cough. Also, we did not find a significant correlation between smoking and cough in this study $(P=0.64)$.

Comparable to the finding from several systematic reviews [8, 32, 39], we found respondents who sought private health care and/or had self-medicated before TB diagnosis were $23 \%$ more likely to experience a longer time to diagnosis. The overarching theme of private health care seeking and/or self-medicating before TB diagnosis derived from IDIs was a prominent barrier to early diagnosis. In Cambodia, free TB services are largely provided by the public healthcare sector, where persons diagnosed with TB are registered and receive treatment. The private health providers mostly do not provide direct TB care and anti-TB medications, and the notification rate remains poor $[15,40]$. However, $67 \%$ of the Cambodian population prefer to seek first treatment in the private healthcare sector due to ease of access, drugs supply, and responsiveness $[41,42]$, with more than two-thirds of the out-of-pocket payments for health care going to the private sector [43]. Hence, the private sector plays a significant role in the cascade of care, and revitalizing and contextualizing the public-private mix programs will be instrumental in finding the missing cases in Cambodia through referrals and public education [40, 44].

This study found that TB stigma contributed to delayed TB diagnosis and IDI participants further elaborated on the shame, embarrassment, and discrimination 
that they both perceived and experienced in the course of their TB care pathway. However, investigations on the relationship between stigma and diagnostic delay have produced mixed results [14]. In Thailand, the impact of TB stigma on time to diagnosis was found to be nonsignificant [45]. However, the effect of stigma on healthseeking behaviors was more pronounced in China [46], in accord with a 2014 systematic review [47]. The disagreements could be contributed by the use of different means of measurement [14]. As stigmatization is a cultural and social phenomenon [47], utilization of validated measurement tools [23] and incorporation of qualitative assessment of TB stigma will provide a more holistic insight into the role of stigma in affecting careseeking behaviors. Nevertheless, the development of contextualized interventions aimed at addressing stigma will be pivotal in shortening the time to TB diagnosis.

The median time from TB diagnosis to treatment initiation was two days, and this finding showed that people with TB in Cambodia were timely treated in accordance with the national guideline (not exceeding three days from the day of diagnosis) [15]. In this study, $75 \%$ of the participants-initiated TB treatment within 3 days from the day of diagnosis. We did not find significant differences between urban and rural dwellers regarding treatment delay. This reflects the success of a decentralized DOTS program to all health centers in Cambodia, resulting in greater access and shorter delay to TB treatment $[15,48]$. We found participants diagnosed with TB by smear microscopy were $50 \%$ more likely to experience a longer time to treatment initiation. This is congruent with a longer reporting time required by smear microscopy compared with GeneXpert MTB/RIF [49]. The utilization of point-of-care diagnostic tools such as GeneXpert MTB/RIF should be further optimized to improve case detection, timely diagnosis, and treatment of TB, and cost-effectiveness [50-52].

This study has several limitations. The onset of symptoms was self-reported by study participants and subjected to recall bias. To reduce the recall bias, we trained data collectors to interview participants within 1 month of diagnosis. Significant cultural and public holidays in Cambodia were used as prompts to aid recall and facilitate the estimation of the date of the onset of symptoms. Second, our sampling frame did not include all the ODs in Cambodia, hence limiting the generalizability of the findings to all people with TB in Cambodia. To assess the representativeness of our sample, we compared our findings with other nationally representative studies. Despite an overrepresentation of participants living in urban settings (36.9\% vs $21.4 \%$ in the national census [34]), the ratio of men to women (1.3), and the proportion of bacteriologically confirmed TB by age groups (Supplementary Table 2) were comparable to the previous national TB prevalence survey [53]. The distance from home to the nearest public health facility reported in this study is also comparable to other studies conducted in Cambodia [33, 54, 55]. Hence, we believe the limitation on generalizability is minimal. In the assessment of private health care engagement and self-medication prior to TB diagnosis, we were not able to distinguish the frequency of these actions in this study. Therefore, we took the binary approach of either sought private health care and/or had self-medicated before TB diagnosis or not in the final analysis. To our knowledge, this is the first study to assess the extent and determinants of TB diagnostic and treatment delay in Cambodia. As there is no universal cut-off for diagnostic and treatment delay, we analyzed the outcome of interest in its continuous form to preserve as much information possible [56]. In the qualitative study, we undertook a long versus short delay analysis approach-with equal representation by gender and urban/rural dwellings for multifarious perspectives. We adopted the explanatory sequential design in this study for a comprehensive understanding of the findings, and the cogency of findings is further strengthened through the corroboration of both quantitative and qualitative data.

\section{Conclusions}

In conclusion, we found that people with TB experienced substantial delays before being diagnosed with TB. Seeking private healthcare and self-medication before TB diagnosis; absence of TB symptoms such as cough, hemoptysis, and night sweats; stigma; rural residence; and a lower education level were responsible for longer delays. Delays in TB care-seeking for more than 2 months have shown to elevate the risk of household infection, and infectivity declined rapidly after the initiation of treatment [57]. Longer treatment delay was noted among TB diagnoses made using sputum-smear microscopy. Increasing public awareness about TB and consciousness regarding stigma, engaging the private healthcare providers, and tailoring approaches to target the rural areas could further improve early detection of TB and narrowing the gap of missing cases in Cambodia.

\section{Supplementary information}

Supplementary information accompanies this paper at https://doi.org/10. 1186/s40249-020-00665-8.

\section{Additional file 1.}

\section{Abbreviations}

ACF: Active case finding; aHR: Adjusted hazard ratios; CENAT: National Center for Tuberculosis and Leprosy Control; Cl: Confidence interval; DOTS: Directly observed treatment, short-course; GHQ: General health questionnaire; HIV: Human immunodeficiency virus; IDI: In-depth interview; IQR: Interquartile range; MTB/RIF: Mycobacterium tuberculosis/rifampicin resistance; NECHR: National Ethic Committee for Health Research; NUS IRB: National University of Singapore Institutional Review Board; OD: Operational district; 
PCF: Passive case finding; SD: Standard deviation; TB: Tuberculosis; USD: United States dollar; WHO: World Health Organization

\section{Acknowledgments}

We would like to thank the study participants for their contribution to this project. We would also like to acknowledge the contribution of the National Center for Tuberculosis and Leprosy Control Cambodia, Dr. Chansophal Ly, Mr. Seyha Ong, and the field staff in coordinating the training and data collection processes. We would like to thank Dr. Kiesha Prem for her advice on the study design and statistical methods used in this study.

\section{Authors' contributions}

AKJT, LYH, and SY conceptualized the study, designed the study and developed the study methods. AKJT, LYH, and SY wrote the grant application to obtain funding. AKJT, NS, LYH, and SY obtained ethical approvals for the project. AKJT, OC, SE, NS, and ST oversaw project implementation, data collection, curation, and processing. AKJT and SY analyzed the data and interpreted the results. AKJT, CO, SE, and ST contributed to the drafting of the manuscript. All authors reviewed and approved the final manuscript.

\section{Funding}

This project is supported by the Saw Swee Hock School of Public Health Infectious Diseases Program Research Grant and the National University of Singapore President's Graduate Fellowship. The funders had no role in the design of the study and collection, analysis, and interpretation of data and in writing the manuscript.

\section{Availability of data and materials}

The datasets used and/or analyzed during the current study are available from the corresponding author on reasonable request.

\section{Ethics approval and consent to participate}

This study was approved by the National Ethics Committee for Health Research Cambodia (NECHR reference: 024/NECHR) and the National University of Singapore Institutional Review Board (REF No. N-19-015). Informed consent was obtained from all respondents before study enrolment.

\section{Consent for publication}

\author{
Not applicable.
}

\section{Competing interests}

The authors declare that they have no competing interests.

\section{Author details}

'Saw Swee Hock School of Public Health, National University of Singapore, National University Health System, Singapore, Singapore. ${ }^{2}$ KHANA Center for Population Health Research, Phnom Penh, Cambodia. ${ }^{3}$ Yong Loo Lin School of Medicine, National University of Singapore and National University Health System, Singapore, Singapore. ${ }^{4}$ Center for Global Health Research, Touro University California, Vallejo, USA. ${ }^{5}$ School of Public Health, National Institute of Public Health, Phnom Penh, Cambodia.

\section{Received: 4 March 2020 Accepted: 23 April 2020}

\section{Published online: 07 May 2020}

\section{References}

1. World Health Organization. Global tuberculosis report 2019. Geneva: World Health Organization; 2019.

2. Khieu K, Ito K, Hamajima N. Experience in tuberculosis treatment through directly observed therapy short course in health centres and communities in Cambodia. Public Health. 2007;121:696-9.

3. World Health Organization. Systematic screening for active tuberculosis: principles and recommendations. Geneva: World Health Organization; 2013.

4. Morishita F, Eang MT, Nishikiori N, Yadav R-P. Increased case notification through active case finding of tuberculosis among household and Neighbourhood contacts in Cambodia. PLoS One. 2016;11:e0150405.

5. Golub JE, Bur S, Cronin WA, Gange S, Baruch N, Comstock GW, et al. Delayed tuberculosis diagnosis and tuberculosis transmission. Int J Tuberc Lung Dis. 2006;10:24-30.
6. Jassal MS, Bishai WR. The epidemiology and challenges to the elimination of global tuberculosis. Clin Infect Dis. 2010;50:S156-64.

7. The Global Fund to Fight AIDS, Tuberculosis and Malaria. Make a global priority of finding missing cases of tuberculosis. 2017. https://www. theglobalfund.org/en/blog/2017-10-10-make-a-global-priority-of-findingmissing-cases-of-tuberculosis/. Accessed 11 July 2018.

8. Getnet F, Demissie M, Assefa N, Mengistie B, Worku A. Delay in diagnosis of pulmonary tuberculosis in low-and middle-income settings: systematic review and meta-analysis. BMC Pulm Med. 2017;17:202.

9. de Vries SG, Cremers AL, Heuvelings CC, Greve PF, Visser BJ, Bélard S, et al. Barriers and facilitators to the uptake of tuberculosis diagnostic and treatment services by hard-to-reach populations in countries of low and medium tuberculosis incidence: a systematic review of qualitative literature. Lancet Infect Dis. 2017;17:e128-43.

10. Teo AKJ, Singh SR, Prem K, Hsu LY, Yi S. Determinants of delayed diagnosis and treatment of tuberculosis in high-burden countries: a mixed-methods systematic review and meta-analysis. 2020. https://www.researchsquare.com/ article/6dbe6955-78e6-49ec-9249-a0ae9baffe8c/v1. Accessed 14 Mar 2020.

11. Sundaram N, James R, Sreynimol U, Linda P, Yoong J, Saly S, et al. A strong TB programme embedded in a developing primary healthcare system is a lose-lose situation: insights from patient and community perspectives in Cambodia. Health Policy Plan. 2017;32:ii32-42.

12. Craig GM, Daftary A, Engel N, O'Driscoll S, loannaki A. Tuberculosis stigma as a social determinant of health: a systematic mapping review of research in low incidence countries. Int J Infect Dis. 2017;56:90-100.

13. Kipp A, Pungrassami P, Stewart P, Chongsuvivatwong V, Strauss R, Van Rie A. A prospective study of TB and AIDS stigma as barriers to TB treatment adherence using validated stigma scales. Int J Tuberc Lung Dis. 2011;15: 1540-i.

14. Courtwright A, Turner AN. Tuberculosis and stigmatization: pathways and interventions. Public Health Rep. 2010;125:34-42.

15. National Center for Tuberculosis and Leprosy Control (CENAT). Technica guidelines on tuberculosis control. 2nd ed. Phnom Penh: Ministry of Health; 2016

16. United Nations Population Fund. Report on urbanization and its linkage to socio-economic and environmental issues. Phnom Penh: Cambodia; 2014.

17. Asian Development Bank. Cambodia: urban sector assessment, strategy and road map. Manila: Asian Development Bank; 2012.

18. World Health Organization. Advocacy, communication and social mobilization for TB control: a guide to developing knowledge, attitude, and practice surveys. Geneva: World Health Organization; 2008.

19. Goldberg DP, Gater R, Sartorius N, Ustun TB, Piccinelli M, Gureje O, et al. The validity of two versions of the $\mathrm{GHQ}$ in the WHO study of mental illness in general health care. Psychol Med. 1997;27:191-7.

20. Goldberg D, Williams P. A user's guide to the general health questionnaire. Windsor: NFER-Nelson; 1988.

21. Desale A, Ali I, Esmael A, Yaregal Z, Desta K, Agonafir M. Assessment of patients' knowledge, attitude, and practice regarding pulmonary tuberculosis in eastern Amhara regional state, Ethiopia: cross-sectional study. Am J Trop Med Hyg. 2013:88:785-8.

22. Van Rie A, Sengupta S, Pungrassami P, Balthip Q, Choonuan S, Kasetjaroen $Y$, et al. Measuring stigma associated with tuberculosis and HIV/AIDS in southern Thailand: exploratory and confirmatory factor analyses of two new scales. Tropical Med Int Health. 2008:13:21-30.

23. Meershoek A, Zwerling A, Daftary A, Citro B, Smyth C, Lewis D, et al. TB stigma measurement guidance. Den Haag: KNCV Tuberculosis Foundation; 2018.

24. KoBoToolbox. KoBoToolbox: data collection tools for challenging environments. 2019. https://kobotoolbox.org/. Accessed 4 Oct 2019.

25. Akaike H. A new look at the statistical model identification. IEEE Trans Autom Control. 1974;19:716-23.

26. Schoenfeld D. Chi-squared goodness-of-fit tests for the proportional hazards regression model. Biometrika. 1980;67:145-53.

27. Martinez L, Xu L, Chen C, Sekandi JN, Zhu Y, Zhang C, et al. Delays and pathways to final tuberculosis diagnosis in patients from a referral Hospital in Urban China. Am J Trop Med Hyg. 2017;16:0358.

28. Ahmad RA, Mahendradhata Y, Utarini A, de Vlas SJ. Diagnostic delay amongst tuberculosis patients in Jogjakarta Province, Indonesia is related to the quality of services in DOTS facilities: diagnostic delay amongst TB patients in Jogjakarta Province. Tropical Med Int Health. 2011;16:412-23.

29. Kahsay A, Gedefaw M, Asres M, Weldu Y. Patients' delay in seeking health Care for Tuberculosis Diagnosis in East Gojjam zone, Northwest Ethiopia. Am J Trop Med Hyg. 2017;96:1071-5. 
30. Satyanarayana S, Nair SA, Chadha SS, Sharma G, Yadav S, Mohanty S, et al. Health-care seeking among people with cough of 2 weeks or more in India. Is passive TB case finding sufficient? Public Health Action. 2012;2:157-61.

31. Chanda-Kapata P, Kapata N, Masiye F, Maboshe M, Klinkenberg E, Cobelens F, et al. Health Seeking Behaviour among Individuals with Presumptive Tuberculosis in Zambia. PLoS One. 2016;11:e0163975 van Zyl-Smit R, editor.

32. Li Y, Ehiri J, Tang S, Li D, Bian Y, Lin H, et al. Factors associated with patient, and diagnostic delays in Chinese TB patients: a systematic review and metaanalysis. BMC Med. 2013;11:156.

33. Prem K, Pheng SH, Teo AKJ, Evdokimov K, Nang EEK, Hsu LY, et al. Spatial and temporal projections of the prevalence of active tuberculosis in Cambodia. BMJ Glob Health. 2019;4:e001083.

34. National Institute of Statistics. Cambodia inter-censal population survey 2013. Phnom Penh: Ministry of Planning; 2014.

35. Eang MT, Peou S, Yadav RP, Morishita F, Nishikiori N, van Maaren P, et al. Early detection of tuberculosis through community-based active case finding in Cambodia. BMC Public Health. 2012;12:1-9.

36. Yimer S, Holm-Hansen C, Yimaldu T, Bjune G. Health care seeking among pulmonary tuberculosis suspects and patients in rural Ethiopia: a community-based study. BMC Public Health. 2009;9:454.

37. Machado AC, Steffen RE, Oxlade O, Menzies D, Kritski A, Trajman A. Fatores associados ao atraso no diagnóstico da tuberculose pulmonar no estado do Rio de Janeiro. J Bras Pneumol. 2011;37:512-20.

38. Xia D, Zhang Z, Li X, Jiang C, Ma J, Ding S, et al. Factors associated with patient delay among new tuberculosis patients in Anqing, China. Biomed Res. 2016;27:8

39. Storla DG, Yimer S, Bjune GA. A systematic review of delay in the diagnosis and treatment of tuberculosis. BMC Public Health. 2008:8:15.

40. Bell CA, Eang MT, Dareth M, Rothmony E, Duncan GJ, Saini B. Provider perceptions of pharmacy-initiated tuberculosis referral services in Cambodia, 2005-2010. Int J Tuberc Lung Dis. 2012;16:1086-91.

41. National Institute of Statistics (NIS). Demographic health survey 2014. Phnom Penh: Ministry of Planning; 2015.

42. Berendes S, Heywood P, Oliver S, Garner P. Quality of private and public ambulatory health care in low and middle income countries: systematic review of comparative studies. PLoS Med. 2011;8:e1000433 Jenkins $\mathrm{R}$, editor.

43. Ministry of Health Cambodia, World Health Organization Regional Office for the Western Pacific. Health service delivery profile. Cambodia; 2012. http:// www.wpro.who.int/health_services/service_delivery_profile_cambodia.pdf. Accessed 14 Oct 2019

44. Lei X, Liu Q, Escobar E, Philogene J, Zhu H, Wang Y, et al. Public-private mix for tuberculosis care and control: a systematic review. Int J Infect Dis. 2015; 34:20-32.

45. Pungrassami $P$, Kipp A, Stewart $P$, Chongsuvivatwong $V$, Strauss $R$, Van Rie A. Tuberculosis and AIDS stigma among patients who delay seeking care for tuberculosis symptoms. Int J Tuberc Lung Dis. 2010;14:181-7.

46. Duan Q, Wang P, Lv J, Zhong R, Wang W. Health care seeking among pulmonary tuberculosis suspects in Wuhan: A community-based study. Int J Med Med Sci. 2013;5:273-8.

47. Chang $\mathrm{S}-\mathrm{H}$, Cataldo JK. A systematic review of global cultural variations in knowledge, attitudes and health responses to tuberculosis stigma. Int J Tuberc Lung Dis. 2014;18(6):168-73.

48. Saly S, Onozaki I, Ishikawa N. Decentralized DOTS shortens delay to TB treatment significantly in Cambodia. Kekkaku. 2006;81:467-74.

49. Lee H-S, Kee S-J, Shin J-H, Kwon Y-S, Chun S, Lee JH, et al. Xpert MTB/RIF assay as a substitute for smear microscopy in an intermediate-burden setting. Am J Respir Crit Care Med. 2019;199:784-94.

50. Creswell J, Codlin AJ, Andre E, Micek MA, Bedru A, Carter EJ, et al. Results from early programmatic implementation of Xpert MTB/RIF testing in nine countries. BMC Infect Dis. 2014;14:2

51. Laushkina Z, Cherednichenko A. Estimation of the role of the test GeneXpert MTB-RIF in the diagnosis of pulmonary tuberculosis. Eur Respir J. 2014:44:P2677

52. Pallas SW, Courey M, Hy C, Killam WMP, Warren D, Moore B. Cost analysis of tuberculosis diagnosis in Cambodia with and without Xpert ${ }^{\circledast}$ MTB/RIF for people living with HIV/AIDS and people with presumptive multidrug-resistant tuberculosis. Appl Health Econ Health Policy. 2018; 16:537-48.
53. National Center for Tuberculosis and Leprosy Control (CENAT). Second national prevalence survey, 2011. Phnom Penh: Ministry of Health; 2012.

54. Jacobs B, Bajracharya A, Saha J, Chhea C, Bellows B, Flessa S, et al. Making free public healthcare attractive: optimizing health equity funds in Cambodia. Int J Equity Health. 2018;17:88.

55. Hwang WJ, Park YM. Factors influencing the accessibility of maternal health Service in Cambodia. Int J Environ Res Public Health. 2019;16:2909.

56. Altman DG, Royston P. The cost of dichotomising continuous variables. BMJ. 2006;332:1080.

57. Riley RL, Moodie AS. Infectivity of patients with pulmonary tuberculosis in inner city homes. Am Rev Respir Dis. 1974;110:810-2.

\section{Ready to submit your research? Choose BMC and benefit from:}

- fast, convenient online submission

- thorough peer review by experienced researchers in your field

- rapid publication on acceptance

- support for research data, including large and complex data types

- gold Open Access which fosters wider collaboration and increased citations

- maximum visibility for your research: over $100 \mathrm{M}$ website views per year

At BMC, research is always in progress.

Learn more biomedcentral.com/submissions 